\title{
Some Measurements of Balloon Motions with Doppler Radar
}

\author{
G. E. McVehIL, R. J. PIIIE ANd G. A. Zigrossi \\ Cornell Aeronautical Laboratory, Inc., Buffalo, N. Y.
}

(Manuscript received 19 March 1964, in revised form 4 May 1964)

\begin{abstract}
Ascending one- and two-meter diameter spherical balloons have been tracked with a pulse Doppler radar to determine the characteristics of the radial component of balloon velocity. Spectral analysis of the velocity records reveals oscillations with wavelengths between 12 and 80 meters which are believed to be aerodynamically induced rather than of meteorological origin. The oscillations of the two-meter balloons are of larger amplitude and longer wavelength than those of the one-meter balloons. Evidence is presented indicating that the characteristics of the oscillations are dependent on Reynolds number.
\end{abstract}

As part of a Laboratory supported program to determine how well meteorological balloons trace the wind, several one- and two-meter metalized spherical balloons were tracked with a pulse Doppler radar at Cornell Aeronautical Laboratory in June and July 1963. The range-gated signal from a rising passive balloon was passed through a discriminator circuit which generated a voltage proportional to the Doppler-shift frequency corresponding to the radial velocity component of the balloon. The output of the discriminator consequently gave a continuous record of the radial velocity of the balloon. All measured velocities mentioned in this note refer to the radial component of velocity in the pointing direction of the radar. It was observed that the velocity traces contained oscillations that, because of their apparent regularity, were more likely caused by the aerodynamic characteristics of the balloon than by atmospheric turbulence or wind shear.

An example of such a trace is shown in Fig. 1a. The target in this case was a two-meter balloon. ${ }^{1}$ The oscillations in its radial velocity are clearly apparent in the record. An 8-min portion of this record was subjected to a statistical analysis. During this period the balloon was ascending from two to six $\mathrm{km}$ above the ground and the average speed away from the radar was $11 \mathrm{~m} \mathrm{sec}^{-1}$. The standard deviation of the velocity was found to be $2.52 \mathrm{~m} \mathrm{sec}^{-1}$. The power spectrum of the velocity fluctuations is plotted in Fig. 1b. Points were read off the trace at intervals of $0.4 \mathrm{sec}$ and 160 lags were used in the spectral computation. Examples of the 80 per

' Halloons used were of the metalized spherical variety, manufactured by G. T. Schjeldahl Company, Northfield, Minn. The two-meter balloons were provided us by the George C. Marshall Space Flight Center, National Áeronautics and Space Administration. cent confidence limits of spectral estimates, computed from formulas of Blackman and Tukey (1958), are shown on the figure. The portion of the spectrum between about 0.1 and $0.25 \mathrm{cps}$ shows somewhat more energy than would be expected in typical spectra of atmospheric motions. Since the balloon was rising at an average rate of about $8 \mathrm{~m} \mathrm{sec}^{-1}$, these frequencies correspond to wavelengths of 30 to $80 \mathrm{~m}$ and are believed to be the result of motions of the sphere induced by aerodynamic forces. Optical observation of the balloon confirmed that lateral oscillations were taking place. Spurious balloon motions were probably also present at longer wavelengths, as reported by Scoggins (1964), but we have made no attempt to separate such motions from possible meteorological irregularities having the same scales.

It is plausible that the oscillations might be associated with the turbulence in the boundary layer flow about the balloon. Wind tunnel data indicate that flow around spheres becomes turbulent when the Reynolds number exceeds a critical value lying somewhere between $0.8 \times 10^{5}$ and $3 \times 10^{5}$ (cf. Dryden el al., 1956). For balloons in the free atmosphere, the transition region is probably broader and less well-defined. The two-meter balloon operates generally at supercritical Reynolds numbers, but the flow about a one-meter balloon is nearly subcritical in much of the troposphere.

Power spectra of Doppler-measured radial velocity fluctuations of a one-meter balloon are shown in Fig. 2 . Again 8-min records were used and points were read off at $0.4 \mathrm{sec}$ intervals. In these cases, 83 lags were used in the computations. Fig. 2a shows a spectrum from the first portion of a flight where the mean Reynolds number was approximately $2.6 \times 10^{5}$, or marginally supercritical. The peak at $0.33 \mathrm{cps}$ is more distinct than any in the 

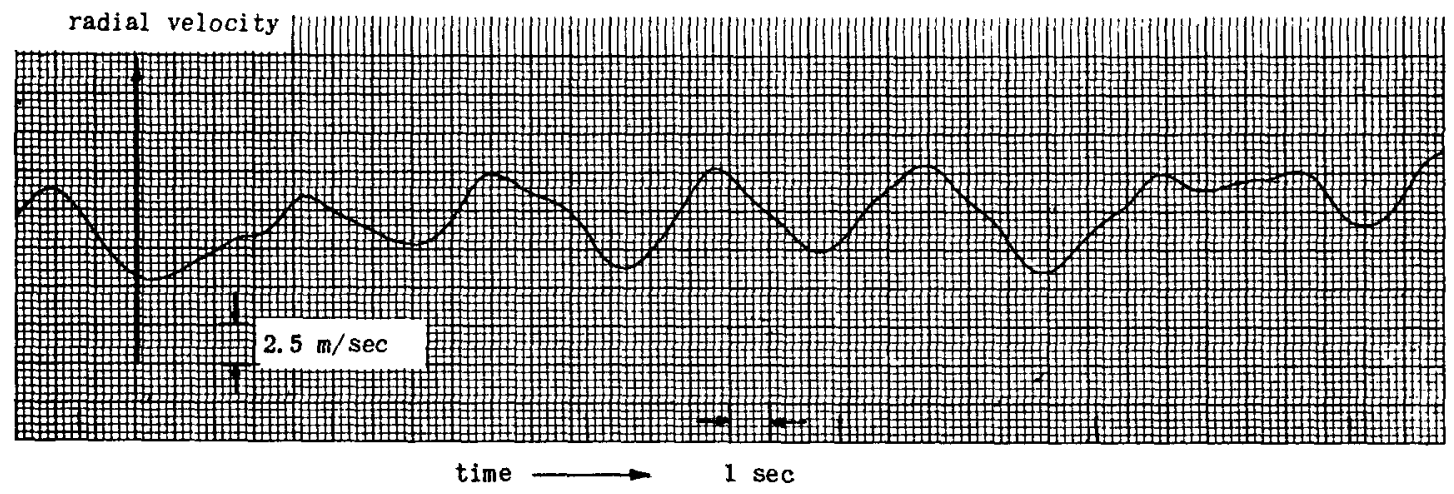

Fig. 1a. Sample of Doppler frequency tracker record for two-meter balloon run, 9 June 1963.

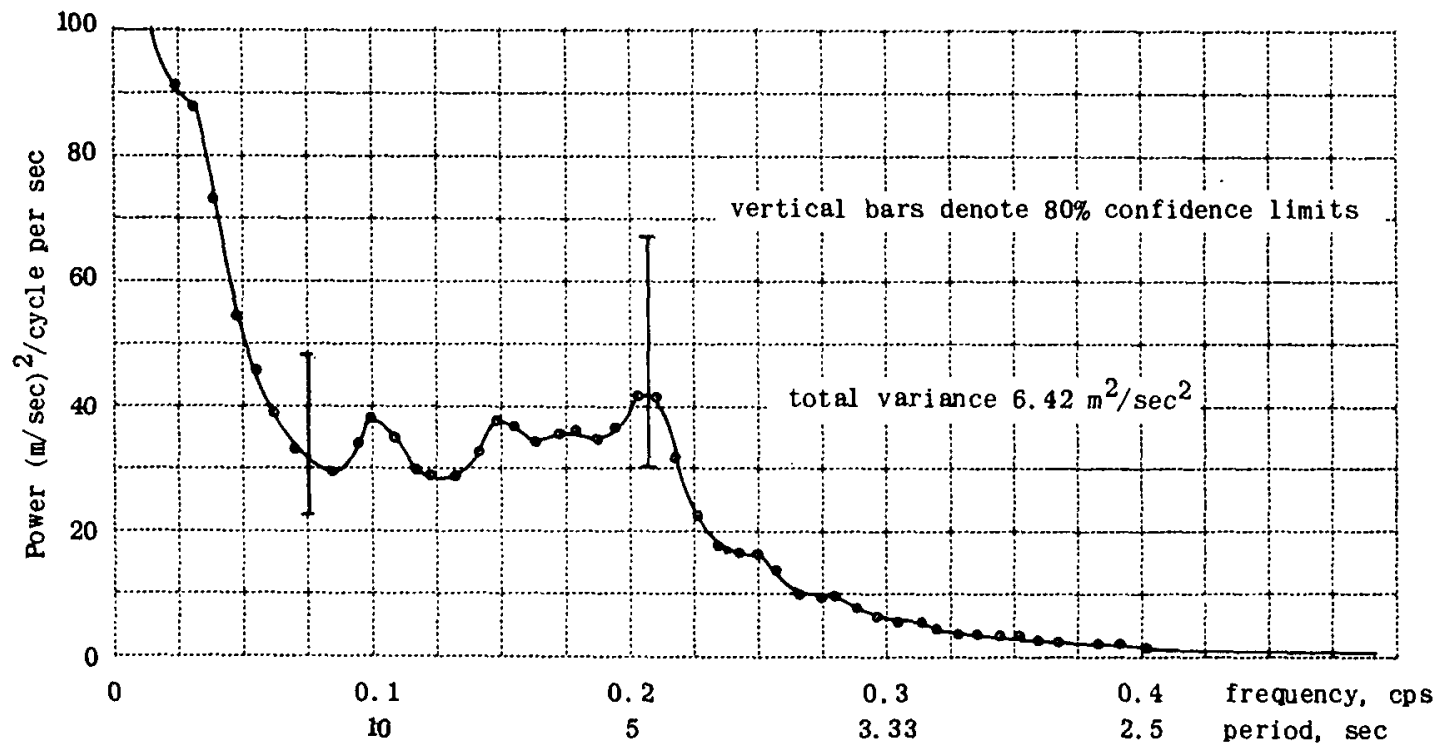

FIG. 1b. Spectrum of radial velocity for two-meter balloon. Altitude range 2 to $6 \mathrm{~km}, 9$ June 1963 .

two-meter balloon spectrum. The mean radial velocity component during the run was about $11 \mathrm{~m} \mathrm{sec}^{-1}$ and the standard deviation was $0.98 \mathrm{~m} \mathrm{sec}^{-1}$. The peak corresponds to a vertical wavelength of about $15 \mathrm{~m}$.

In Fig. $2 b$ is shown the power spectrum from a higher portion of the same ascent. Here the mean Reynolds number was about $1.2 \times 10^{5}$. There are two obvious peaks, one at higher and one at lower frequency than the peak in the low level spectrum. The mean radial velocity was about $9 \mathrm{~m} \mathrm{sec}^{-1}$ and the standard deviation was $1.17 \mathrm{~m} \mathrm{sec}^{-1}$. The spectral peaks imply the existence of oscillations with vertical wavelengths of $8 \mathrm{~m}$ and $15 \mathrm{~m}$.

It is apparent that the decrease in Reynolds number during the one-meter balloon run did not eliminate the balloon oscillations. We cannot be certain that a transition from turbulent to laminar flow occurred between the altitudes at which the two spectra were taken since the critical Reynolds number is not sharply defined for a free balloon. Yet the balloon vertical velocity, computed from the elevation angle and range information, decreased from $5 \mathrm{~m} \mathrm{sec}^{-1}$ at $1 \mathrm{~km}$ to $3 \mathrm{~m} \mathrm{sec}^{-1}$ at $5 \mathrm{~km}$, implying an increase in drag as would occur in transition.

One concludes from these data that one- and twometer spherical balloons do not move entirely with the wind but have spurious oscillatory components that are aerodynamically induced. The frequencies and amplitudes of these components appear dependent upon the Reynolds number, the exact relationship currently being sought. Additional experiments under the sponsor- 


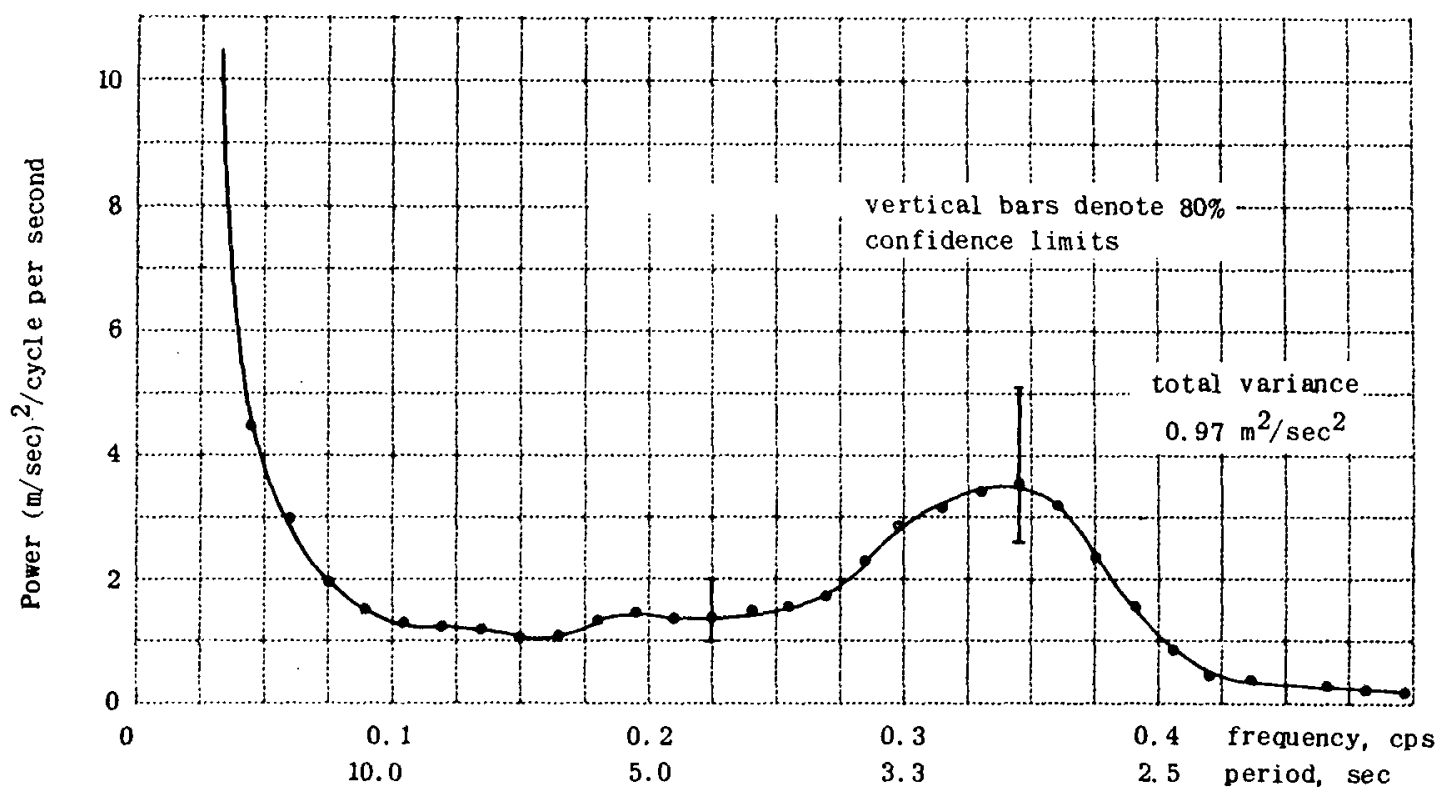

FIG. 2a. Spectrum of radial velocity for one-meter balloon. Altitude range 0.8 to $3.0 \mathrm{~km}$, 26 June 1963 .

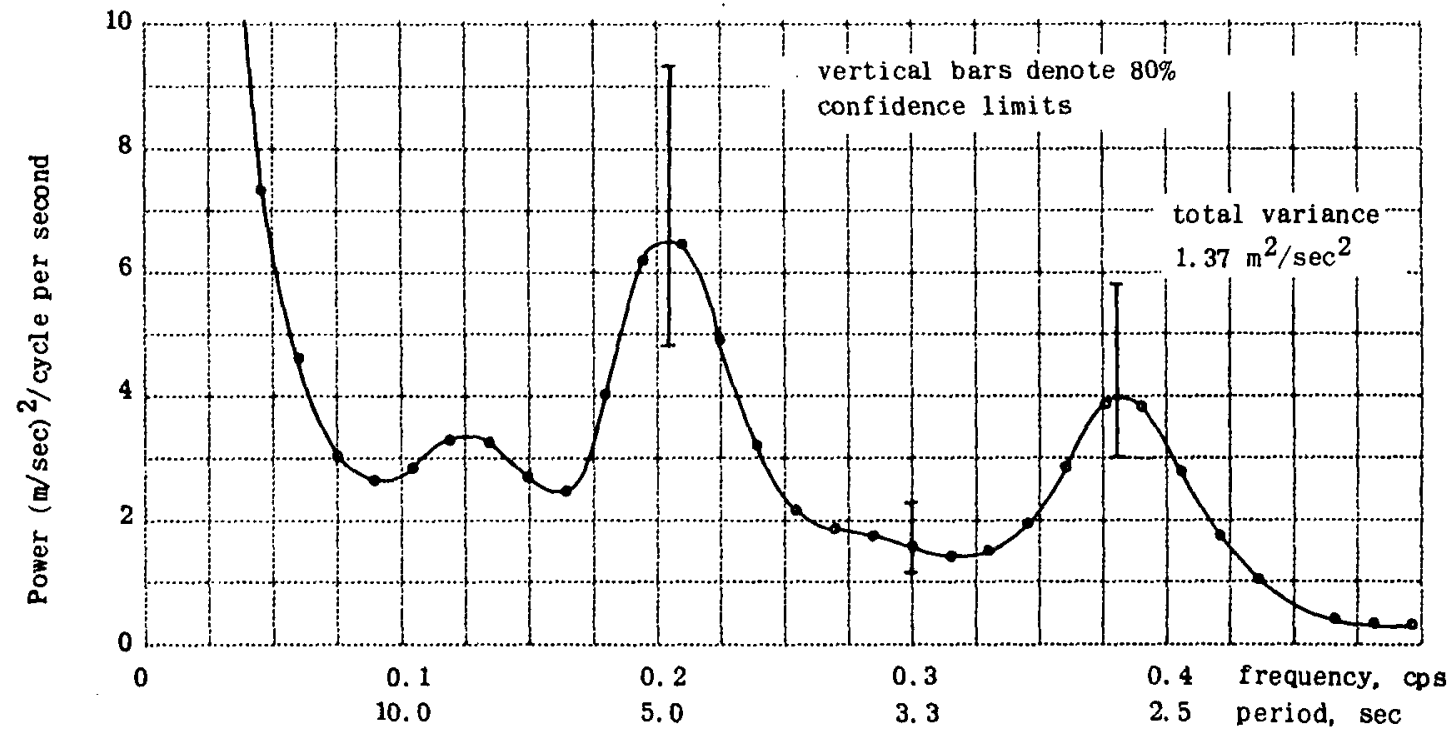

Fig. 2b. Spectrum of radial velocity for one-meter balloon. Altitude range 4.3 to $5.8 \mathrm{~km}, 26$ June 1963 .

ship of the George C. Marshall Space Flight Center, National Aeronautics and Space Administration are planned. Different balloon sizes and configurations will be tested under different meteorological conditions in order to determine more specifically the characteristics of spurious balloon motions.

\section{REFERENCES}

Blackman, R. B., and J. W. Tukey, 1958: The Measurement of Power Specira. Dover Publications, New York, pp. 22, 23.

Dryden, H. L., F. D. Murnaghan and H. Bateman, 1956: Hydrodynamics. New York, Dover Publications, p. 10.

Scoggins, J. R., 1965: Spherical balloon wind sensor behavior. J. Appl. Meteor., 4, 139-145. 